\title{
Traumatic cavernous internal carotid artery pseudoaneurysm presenting with massive epistaxis-a morbid clinical entity
}

\author{
Santosh Kumar Swain*
}

\begin{abstract}
Department of Otorhinolaryngology, IMS and SUM hospital, Siksha “O” Anusandhan University, Kalinganagar, Bhubaneswar, Odisha, India
\end{abstract}

Received: 14 October 2020

Accepted: 13 November 2020

\section{*Correspondence:}

Dr. Santosh Kumar Swain,

E-mail: santoshvoltaire@yahoo.co.in

Copyright: () the author(s), publisher and licensee Medip Academy. This is an open-access article distributed under the terms of the Creative Commons Attribution Non-Commercial License, which permits unrestricted non-commercial use, distribution, and reproduction in any medium, provided the original work is properly cited.

\begin{abstract}
Epistaxis is commonly encountered by clinicians in emergency department. However, severe and recurrent epistaxis is very uncommon especially that arise from the cavernous internal carotid artery (ICA) pseudoaneurysm. Traumatic cavernous internal carotid pseudoaneurysm is a rare cause of the epistaxis but is a fatal and life-threatening clinical condition if left untreated. Massive epistaxis following head injury should alert the clinician to rule out traumatic cavernous ICA pseudoaneurysm. Traumatic pseudoaneurysm of the cavernous part of the ICA is a challenging clinical entity both in diagnosis and treatment. This clinical diagnosis may be suspected in case of patient with history of head injury, massive recurrent epistaxis and delayed onset of blindness. Massive epistaxis after head trauma should alert the clinician for possible cavernous ICA pseudoaneurysm. Carotid angiography confirms the site of pseudoaneurysm. The treatment options are endovascular stent and coil embolization, arterial balloon occlusion and surgical trapping. Timely diagnosis and treatment of this condition give a favorable outcome. In this review article, we discuss the epidemiology, etiopathology, clinical presentations, investigations and current treatment of the traumatic cavernous ICA pseudoaneurysm.
\end{abstract}

Keywords: Internal carotid artery, Pseudoaneurysm, Carotid angiography, Endovascular coiling

\section{INTRODUCTION}

Most of the nasal bleeding or epistaxis after blunt trauma to the head is self-limited and the bleeding often comes from the lacerated nasal mucosa or injury of the sphenopalatine and anterior ethmoidal arteries. ${ }^{1}$ Traumatic cavernous ICA pseudoaneurysm is a rare clinical incidence due to trauma to the head. If this condition is unrecognized, may lead to mortality. Managing this pseudoaneurysm with massive epistaxis is unique in clinical practice and differs from other causes of the epistaxis. Early diagnosis and treatment of the cavernous ICA pseudoaneurysm cannot be overemphasized. Carotid angiography is the gold standard test for confirmation of the diagnosis and also useful to determine the feasibility for endovascular therapy. ${ }^{2}$ Endovascular coil embolization or detachable balloon placement are good treatment options for safe and successful outcome for occluding the cavernous ICA pseudoaneurysm with preservation of the parent artery. As this lesion is potentially hazardous for life, early detection and emergent endovascular treatment procedure is imperative. The clinician should give due importance for finding the anatomical location of the pseudoaneurysm and the timing of the treatment. The objective of this review article is to discuss details of the epidemiology, etiopathology, clinical presentations, investigations and current treatment of the cavernous ICA pseudoaneurysm.

\section{METHODS OF LITERATURE SEARCH}

Research articles regarding cavernous ICA pseudoaneurysm were searched through a multiple 
approach. First, we conducted an online search of the PubMed, SCOPUS, Google Scholar and Medline database with the word cavernous part of internal carotid artery, pseudoaneurysm, massive epistaxis etiopathology, clinical presentations, investigations and current treatment of internal carotid pseudoaneurysm at the cavernous segment. The abstracts of the published article are identified by this search method and other articles were identified manually from the citations. This review article reviews the epidemiology, etiopathology, clinical presentations, diagnosis and current treatment of cavernous ICA pseudoaneurysm. This review article presents a baseline from where further prospective trials can be designed and help as a spur for further research in this clinical entity where not many studies are done.

\section{EPIDEMIOLOGY}

Epistaxis is usually found in otorhinolaryngological practice. Approximately 7 to $60 \%$ of the population experiences at least one episode of the epistaxis of varying severity in their life., ${ }^{3,4}$ Only $6 \%$ of the epistaxis patient needs immediate medical service and the severe intractable cases of the epistaxis are usually rare in clinical practice. ${ }^{5}$ Trauma and vascular abnormalities constitute for less than $5 \%$ of all the cases of epistaxis. ${ }^{6}$ Although head injury is common cause for epistaxis, epistaxis due to traumatic pseudoaneurysm at cavernous ICA is uncommon. Rupture of the pseudoaneurysm at the cavernous part of the ICA can lead to massive epistaxis. Approximately 3 to $5 \%$ of all the intracranial pseudoaneurysm arises from the cavernous part of the ICA. ${ }^{7}$ In one case series (87 cases) of intra-cavernous aneurysm, trauma was found as a causative factor in $8 \%$ of the cases. ${ }^{8}$ This condition may result in mortality is unrecognized and untreated. Majority of this aneurysm are due to head trauma with mortality rate up to $50 \% .^{9}$

\section{ETIOPATHOLOGY}

Post-traumatic epistaxis may be due to injury of the Sino nasal mucosa, coagulopathy or structural problems but the severe of the epistaxis along with history of head injury or skull base fracture raise a high-level suspicion for vascular injury. The traumatic aneurysms in the brain are divided pathologically into true, false/pseudo and mixed types of aneurysms on the basis of the extent of vessel wall disruption. Localized luminal dilation because of the intimal injury, internal elastic layer and media cause a true saccular aneurysm. Traumatic pseudoaneurysm has injury to all the three layers leading formation of a false lumen, contained by adventitia. ${ }^{10}$ Such type of the lesion may be symptom free or present after rupture due to carotid cavernous fistula. Less commonly, this lesion may show epistaxis from rupture of the aneurysm into disrupted sphenoid sinus which can be a life-threatening condition. This aneurysm is called pseudo or false aneurysm because it has no three-layer integrity of the true aneurysm. The traumatic aneurysm wall consists of thrombus and few extra-vascular tissues, this also enhances the risk of rupture. ${ }^{11}$ The massive epistaxis is occurred because of the erosion at the lateral wall of the sphenoid sinus in majority of the cases. The close association of the sphenoid sinus and intracavernous ICA is well known and the cadaveric anatomical study showed ICA bulging into the sinus found in $71 \%$ of the cases. ${ }^{12}$ The bony wall covering the ICA is less than 1 millimeter in around $66 \%$ of the specimens and no bony wall in $4 \%$ of the cases and only covered by dura and sinus mucosa. ${ }^{12}$ The traumatic pseudoaneurysm or aneurysm may occur from shearing forces or hemorrhage in the wall of the artery which weakens it. The duration of the time which weakens the arterial wall may explain the delay of the pseudoaneurysm formation. ${ }^{13}$

There are several mechanisms for explaining the formation of the pseudoaneurysm of ICA after blunt or penetrating injury. Tear at the intimal layer of the ICA can be augmented by dissection of blood, which finally leads to reduced blood flow and formation of thrombus in the lumen. ${ }^{13}$ The process of the arterial weakening is not sudden and the latent period between the trauma and onset of the epistaxis is often variable. This process can take days to years with average duration approximately three weeks ( $88 \%$ of cases). ${ }^{14}$ The pseudoaneurysm of the cavernous ICA is close proximity to the certain vital structures such as cranial nerves II, III, IV, V, VIth and also ophthalmic artery.

\section{CLINICAL PRESENTATIONS}

The characteristic presentation of the patients with posttraumatic cavernous ICA pseudoaneurysm is massive epistaxis in the first minutes but it stops abruptly after loss of several hundreds of millimeters of blood. Some of these patients complain unilateral headache or upper and middle part of the facial paresthesia just prior to the onset of epistaxis. Massive nasal bleeding is usually preceded by one or multiple sentinels' bleeds. So, a high index of suspicion is needed to confirm cavernous ICA pseudoaneurysm as a more serious cause of the nasal bleeding. Epistaxis often starts within one month of the head injury, but may be delayed up to years. ${ }^{15}$ In this condition, epistaxis is massive and recurrent if the diagnosed and treatment is late. Patient of cavernous ICA pseudoaneurysm often present classical findings of massive epistaxis, orbital fracture and proptosis with unilateral blindness (Figure 1). ${ }^{16}$ Early attentions to this triad can give diagnosis of cavernous ICA pseudoaneurysm as the cause of the massive epistaxis so that early intervention can be started. Post-traumatic pseudoaneurysm of the ICA causes epistaxis often within three weeks after initial injury (88\%); however, massive epistaxis may be delayed by months or years. ${ }^{17}$ Early episode of epistaxis is typically is not as severe but in recurrent episodes, the nasal bleeding is more severe. The initial epistaxis may not be impressive and so the diagnosis and treatment may be delayed. In all of the cases except one in our study, the diagnoses were made 
only after massive epistaxis. The explanation for delayed massive epistaxis is by the time required for traumatic event to weaken the ICA wall and the pulsatile pressure to erode via the intact bony wall of the sphenoid sinus. ${ }^{18}$ Rarely the pseudoaneurysm of the cervical ICA rupture into the posterior part of the nasopharynx and eustachian tube. Delayed recurrent or massive epistaxis after head injury should alert the clinician for possibility of the posttraumatic cavernous ICA pseudoaneurysm. This pseudoaneurysm may expand medially and leads to torrential bleeding from the nose.

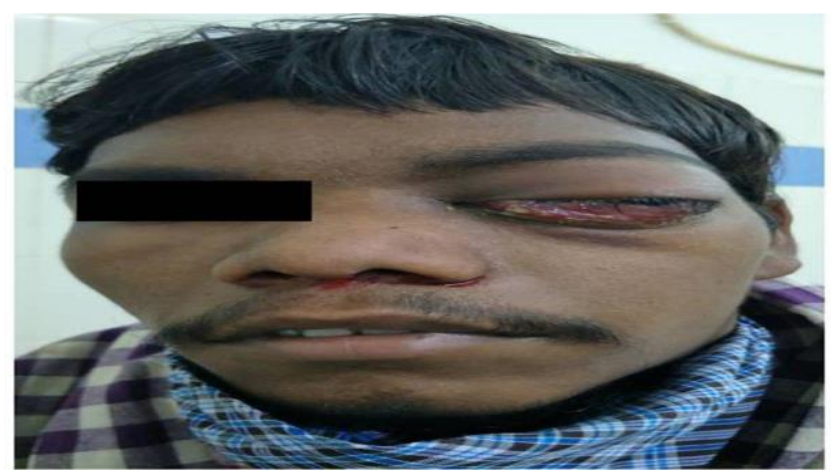

Figure 1: A patient of cavernous ICA pseudoaneurysm presenting with proptosis and blindness in left eye.

\section{INVESTIGATIONS}

It is often difficult to distinguish the blood in the sphenoid sinus which may confuse with origin of blood either result of craniofacial trauma from a pseudoaneurysm of cavernous ICA. Computed tomography (CT) scan remains the ideal imaging to see the fracture in the sphenoid sinus (Figure 2). Magnetic resonance imaging (MRI) has been considered as a diagnostic modality for the pseudoaneurysm protruding into the sphenoid sinus. ${ }^{19}$ However, CT and MRI may mislead the diagnosis in approximately $27 \%$ of the cases where the pseudoaneurysm is confused with intracerebral hematoma or tumor. ${ }^{20}$ The definitive diagnosis is done by angiography revealing the out pouching, contrast filled sac by pseudoaneurysm from the ICA (Figure 3). The pseudoaneurysm often arises from infraclinoid part proximal to the ophthalmic artery and may enlarge to a size which enter and occupy inside the sphenoid sinus and even posterior ethmoid sinuses. The size and shape of the cavernous ICA pseudoaneurysm may change with time by propagation and disintegration of the thrombus inside the arterial lumen. So, head injury patient showing fractures of the sphenoid sinus and massive epistaxis must be evaluated immediately to rule out traumatic pseudoaneurysm. When patient with the head injury showing fractures of the sphenoid sinus without epistaxis, carotid angiography should be deferred for 2 to 3 weeks. If the first angiographic findings are normal, repeat epistaxis should prompt a second angiographic assessment. The chance of the traumatic pseudoaneurysm is very high as $40-60 \%$ occurs after late hemorrhage. ${ }^{21}$

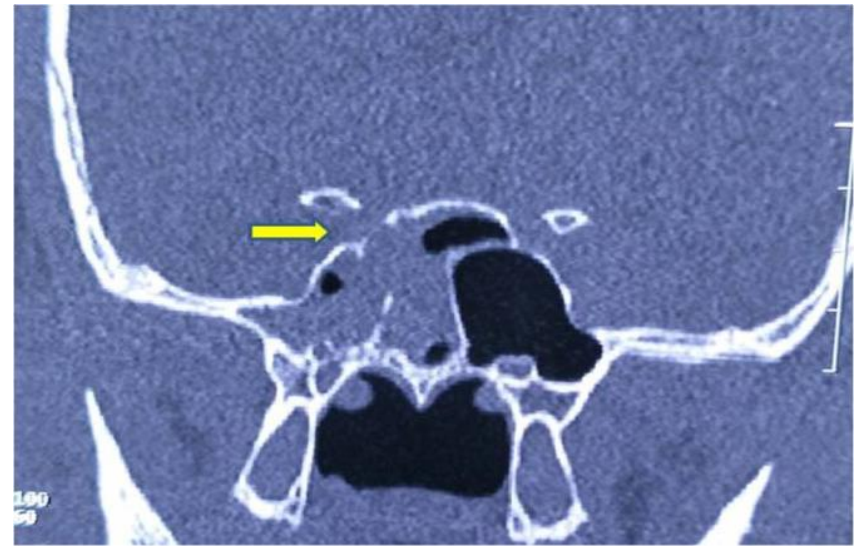

Figure 2: CT scan of the head fracture of the sphenoid sinus and protrusion of the cavernous ICA pseudoaneurysm into the sphenoid sinus.

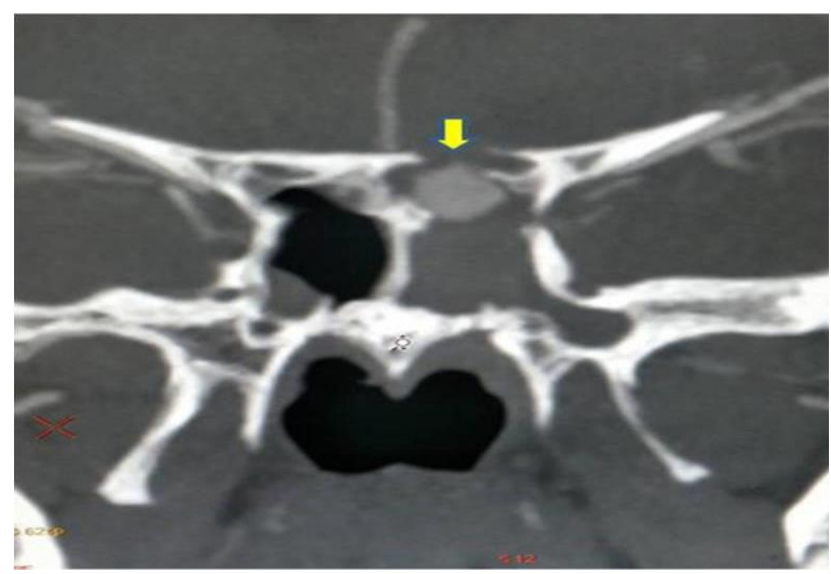

Figure 3: CT angiography of out pouching of the pseudoaneurysm of the cavernous ICA into the sphenoid sinus.

\section{TREATMENT}

The active epistaxis is often managed by anterior and posterior nasal packing along with securing to airway. ${ }^{22}$ In case of severe blood loss, blood transfusion should be done for compensating massive blood loss. ${ }^{23}$ Vaseline gauze mesh or merocele are used for anterior nasal pack whereas Foley catheters may be used for posterior nasal pack. Then the treatment of exact etiology such as the pseudoaneurysm at the cavernous ICA should be done immediately. The treatment can be divided into occlusive and reconstructive. Occlusive approach includes ligation of the parent artery by surgical method or by endovascular technique. Reconstructive approach includes microsurgical clip application, coil embolization with or without vascular reconstruction, flow diverting devices or use of the liquid embolic agents. There are several approaches for treatment of the traumatic pseudoaneurysm at cavernous ICA including sacrificing the parent vessel. These approaches include surgical such as clipping, wrapping, trapping and carotid ligation or endovascular coil (Figure 4). Sacrificing the parent artery 
is not tolerated by the patient and may result in hypoperfusion of the brain and leads to ischemia. Flow diverters are an excellent method for treating complex giant aneurysm where the conventional techniques have failed. ${ }^{24}$ Flow diverters help to improve with an obliteration rate of $60-80 \%$ with morbidity of $10.44 \%$ (9.9-15.2\%) and mortality of $6.86(2.3-9.2 \%) .{ }^{25}$ However, in developing countries, the cost of endovascular treatment is 5-6 times that of the microsurgical bypass. This is an important limitation for endovascular technique and surgical method remains the main stay of the treatment as in index case. ${ }^{26}$

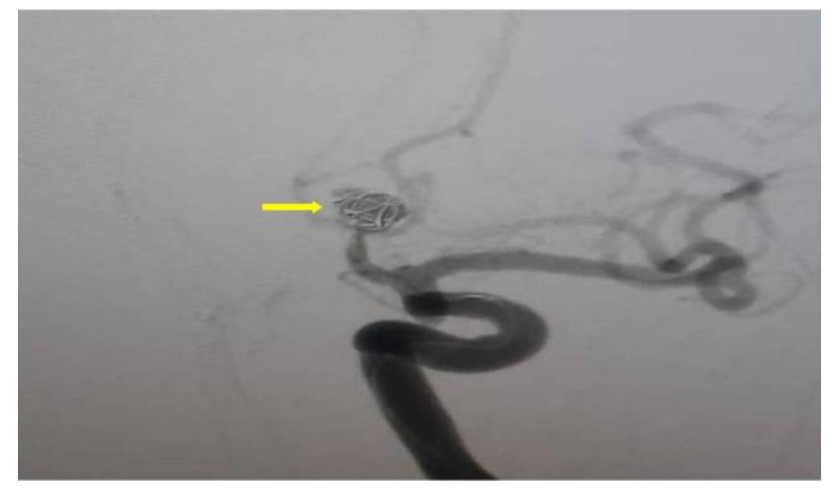

Figure 4: Endovascular coiling of the ruptured pseudoaneurysm of the cavernous ICA.

A patient of cavernous ICA pseudoaneurysm persisting for 7 to 10 days after head injury is an ideal candidate for the stent placement. However, one study recommended that endovascular occlusion of the traumatic pseudoaneurysm is best achieved in the sub-acute phase of the pseudoaneurysm after stabilization and maturity of the pseudoaneurysm wall. ${ }^{27}$ One study reported that approximately $21 \%$ of the complications after endovascular stent treatment are stroke and subclavian artery dissection. Approximately $45 \%$ occlusion rate was found in that study reduced to $5 \%$ in patients treated by thrombotic agents. ${ }^{28}$ Clopidogrel and aspirin are used after endovascular stent implant showing other hemorrhagic chances. In case of occlusion of the ICA lumen, an occlusion tolerance test is done with help of the first detachable balloon. By systemic heparinization, the lumen of the artery is occluded by the detachable inflated balloon at the level of the pseudoaneurysm. Proper neurological assessment such as motor, sensory, speech and memory should be done at the time of the arterial occlusion for 40 to 60 minutes. Blood pressure is maintained in normal range during the test.

The rate of the stroke in patients those undergo abrupt carotid ligation has been documented to be $26 \%$ whereas rate of the stroke in patients those undergo balloon occlusion test is only around $3 \% .{ }^{29}$ In another study approximately 5 to $20 \%$ of the patients those pass the balloon occlusion test result in infarction after permanent occlusion in the affected carotid artery. ${ }^{30}$ The endovascular occlusion of the ICA by using coils may also give rise to risk of the thromboembolic stroke because of the slow flow of the blood along the incompletely occluded artery. ${ }^{31}$ However, the endovascular occlusion of the cavernous ICA pseudoaneurysm with preservation of the parent artery is presently the favored technique. A saccular aneurysm with a small neck is usually embolized with coils. The detachable coils and balloons have a risk of dislodgement through the fragile wall of the pseudoaneurysm. ${ }^{31}$ The bony wall of the sphenoid sinus may give further support to nest of coils which kept in the cavernous ICA pseudoaneurysm. ${ }^{31}$ The latent time between the injury and treatment will permit to mature of the walls of the pseudoaneurysm with fibroblastic elements, so it provides support for the coil mesh. ${ }^{32,33}$

\section{CONCLUSION}

Traumatic cavernous ICA pseudoaneurysm causing massive epistaxis is an uncommon sequel to head injury. It should be anticipated in patients with triad such as history of the head trauma, unilateral blindness and delayed onset massive epistaxis. The high mortality in this case is due to inadequate diagnosis and improper treatment. The diagnosis may be delayed because of the latency period between the head trauma and epistaxis. A high index of suspicion and exact treatment are needed for successful outcome of these patients. Epistaxis should be treated immediately by nasal packing and the diagnosis is confirmed by the angiography at the earliest time. The definitive treatment options include trapping, occlusion by balloon and cervical carotid ligation depending on the expertise and resources available. The treatment must be done earliest in order to prevent mortality.

\section{Funding: No funding sources Conflict of interest: None declared Ethical approval: Not required}

\section{REFERENCES}

1. Guha A, Schalek P, Chovanec M. Syndromes that predispose to epistaxis. European Archives of OtoRhino-Laryngol. 2019;276(4):939-44.

2. Kim JY, Farkas J, Putman CM, Varvares M. Paraclinoid internal carotid artery aneurysm presenting as massive epistaxis. Ann Otol Rhinol Laryngol. 2000;109:782-6.

3. Monux A, Tomas M, Kaiser C, Gavilan J. Conservative management of epistaxis. J Laryngol Otol. 1990;104:868-70.

4. Swain SK, Sahu MC, Baisakh MR. Nasal myiasis in clinical practice. Apollo Med. 2018;15(3):128.

5. Moreau S, De Rugy MG, Babin E, Courtheoux P, Valdazo A. Supraselective embolization in intractable epistaxis: review of 45 cases. Laryngoscope. 1998;108:887-8.

6. Manuel AM, Kalimuthu S, Pathmanathan SS, Narayanan P, Abidin ZZ, Azmi $K$ et al. A. 
Challenges in the management of massive intraorbital and hemifacial arteriovenous malformation as causing life-threatening epistaxis. Asian j sur. 2017;40(2):158-62.

7. Bars HW, Blackwood W, Meadows SP. Intracavernous carotid aneurysms. A clinicalpathological report. Brain. 1971;94:607-22.

8. Higashida RT, Halbach VV, Dowd C, Barnwell SL, Dormandy B, Bell J et al. Endovascular detachable balloon embolization therapy of cavernous carotid artery aneurysms: results in 87 cases. J Neurosurg. 1990;72:857-63.

9. Agarwal V, Phadke RV, Singh V. Posttraumatic internal carotid artery pseudoaneurysm: endovascular management by stent-graft placement. Indian J Neurotrauma. 2016;13(02):116-9.

10. Talamonti G, Aliberti GD and Collice $M$. Management of traumatic intracranial aneurysms. In: Schmidek and Sweets operative neurosurgical techniques: Indications, methods and results. $6^{\text {th }}$ ed. Philadelphia, USA: Elsevier. 2012;1611-8.

11. Krings T, Mandell DM, Kiehl TR Geibprasert S, Geibprasert S, Geibprasert S et al. Intracranial aneurysms: From vessel wall pathology to therapeutic approach. Nat Rev Neurol. 2011;7:54759.

12. Renn WH, Rhoton AL. Microsurgical anatomy of the sellar region. J Neurosurg. 1975;43:288-98.

13. Ghorayeb BY, Kopaniky DR, Yeakley JW. Massive posterior epistaxis: A manifestationof internal carotid injury at the skull base. Arch Otolaryngol Head Neck Surg. 1988;114:1033-37.

14. Radkowski D, McGill TJ, Healy GB, Jones DT. Penetrating trauma of the oropharynx in children. Laryngoscope. 1993;103:991-4.

15. Struffert T, Buhk JH, Buchfelder M, Rohde V, Doerfler A, Knauth M. Coil migration after endovascular coil occlusion of internal carotid artery pseudoaneurysms within the sphenoid sinus. minMinimally Invasive Neurosur. 2009;52(02):89-92.

16. Cohen JE, Ben-Hur T, Gomori JM, Umansky F, Lylyk P, Rajz G. Stent-assisted arterial reconstruction of traumatic extracranial carotid dissections. Neurol Res. 2005;27(1):73-8.

17. Brasiliense LB, Dumont TM. Alarming internal carotid artery aneurysm eroding the sphenoid sinus. World neurosurg. 2017;108:985-e13.

18. Han MH, Sung MW, Chang KH, Min YG, Min YG. Traumatic pseudoaneurysm of the intracavernous ICA presenting with massive epistaxis: imaging diagnosis and endovascular treatment. Laryngoscope. 1994;104:370-7.

19. Goleas J, Mikhael MA, Paige ML, Wolff AP. Intracavernous carotid artery aneurysm presenting as recurrent epistaxis. Ann Otol Rhinol Laryngol. 1991;100:577-9.

20. Linskey ME, Sekhar LN, Hirsch W, Jr., Yonas H, Horton JA. Aneurysms of the intracavernous carotid artery: clinical presentation, radiographic features, and pathogenesis. Neurosur. 1990;26:71-9.

21. Al-Jehani HM, Alwadaani HA, Almolani FM. Traumatic intracranial internal carotid artery pseudoaneurysm presenting as epistaxis treated by endovascular coiling. Neurosci. 2016;21(1):60.

22. Swain SK, Sahu MC. An unusual complication of nasal foreign body in a pediatric patient: A case report. Pediatria Polska. 2017;92(1):111-3.

23. Swain SK, Sahu MC. An unusual giant isolated mucosal malignant melanoma of nasal cavity-A case report. Egyptian J Ear, Nose, Throat and Allied Sci. 2017;18:151-3.

24. Pandey P. Parent vessel occlusion and revascularization: a dying art? Neurol India. 2018;66:657-60.

25. Ambekar S, Madhugiri V, Sharma M, Cuellar H, Nanda A: Evolution of management strategies for cavernous carotid aneurysms: a review. World Neurosurg. 2014;82:1077-85.

26. Sekhar LN, Cheng C-Y, Da Silva HB, Qazi Z: What is the current role of bypass surgery in the management of cerebral aneurysms? Neurol India. 2018;66:661-3.

27. Mendez JC, Gonzalez-Llanos F. Endovascular treatment of a vertebral artery pseudoaneurysm following posterior C1-C2 transarticular screw fixation. Cardiovasc Intervent Radiol. 2005;28:1079.

28. Cothren C, Moore E, Ray C Jr. Carotid artery stents for blunt cerebrovascular injury. Perspect Vasc Surg Endovasc Ther. 2006;18:73.

29. Mathis JM, Barr JD, Jungreis CA, Yonas H, Yonas $\mathrm{H}$, Vincent $\mathrm{D}$ et al. Temporary balloon test occlusion of the internal carotid artery: experience in 500 cases. Am J Neuroradiol. 1995;16:749-54.

30. De Vries EJ, Sekhar LN, Horton JA, Eibling DE, Janecka IP, Schramm VL Jr et al. A new method to predict safe resection of the internal carotid artery. Laryngoscope. 1990;100:85-8.

31. Swain SK, Mohapatra SS. A rare and fatal complication of ear syringing: Rupture of pseudoaneurysm at petrous internal carotid artery. Arch Trauma Res. 2018;7(4):166-8.

32. Lempert TE, Halbach VV, Higashida RT, et al. Endovascular treatment of pseudoaneurysms with electrolytically detachable coils. AJNR Am J Neuroradiol. 1998;19:907-11.

33. Swain SK, Mallik KC. Ear, nose, and throat foreign bodies in pediatric age. Med $\mathrm{J}$ Babylon. 2020;17(3):238.

Cite this article as: Swain SK. Traumatic cavernous internal carotid artery pseudoaneurysm presenting with massive epistaxis-a morbid clinical entity. Int $\mathbf{J}$ Otorhinolaryngol Head Neck Surg 2020;6:2323-7. 